\title{
MUERTE, VIOLENCIA Y SUBJETIVIDAD: UN TRINOMIO TEMÁTICO EN LA NARRATIVA BREVE DE CLAUDIA HERNÁNDEZ
}

\author{
Antonio Núñez \\ University of Oklahoma \\ Norman, OK, Estados Unidos \\ antonio.nunez@ou.edu
}

En 1992, la firma de los acuerdos de paz de Chapultepec daría vuelta de página a los conflictos militares registrados entre las tropas del Frente Farabundo Martí para la Liberación Nacional (FMLN) y el Gobierno de El Salvador entre 1980 y 1992. A raíz de dichos eventos, la llamada literatura de posguerra comenzó a reflejar los cambios sociales que fueron emanando tras el convenio de paz, aunque sin desterrar ni olvidar de la memoria colectiva nacional los atropellos sicológicos provocados por la guerra en la nación centroamericana. Tras el cese al fuego, surge una producción narrativa de manos de escritores salvadoreños que develan, mediante sus creaciones literarias, la angustia y horrores sufridos durante la guerra/posguerra a través de exploraciones escriturales surrealistas, las cuales a menudo se proyectan en una realidad deshumanizante y desencantada.

En la actualidad, dicha labor de reflexión sobre el estropicio y dolor colectivo infligidos por la violencia bélica continúa siendo una temática relevante para las nuevas generaciones de escritores en El Salvador. Tal es el caso de Claudia Hernández, una de las escritoras contemporáneas más destacadas de la literatura salvadoreña de ficción, y cuyas obras exploran temáticas como la violencia, la muerte y la guerra/posguerra, en un estilo narrativo donde la subjetividad y lo cínico integran el tejido de las tramas y personajes creados en las obras de la escritora.

En este artículo se analiza cómo Hernández, a través de la representación simbólica de la muerte y la violencia en los cuentos "Mediodía en la frontera", 
"Manual del hijo muerto" y "Hechos de un buen ciudadano (Partes I y II)", alude y denuncia el trauma sicológico y el estropicio social vivido a raíz de los conflictos bélicos que tomaron lugar en El Salvador en las dos últimas décadas del siglo XX. Estos cuentos fungen dentro de su obra como una especie de recordatorio alegórico de las injusticias en manos del gobierno represor y el movimiento izquierdista en el país centroamericano.

Asimismo, bajo el lente teórico de la estética de la violencia y del cinismo, realizaremos un recorrido por estos relatos breves antes mencionados, para dilucidar cómo y por qué motivos estos trabajos literarios de Hernández son considerados por algunos críticos contemporáneos como obras que pudieran encajar en la perspectiva teórica de la violencia y el cinismo. Además, se incluyen en este análisis otros elementos a tratar, como la revisión del tratamiento del cuerpo y la subjetividad, presentes éstos en muchas de las obras de la cuentista salvadoreña.

Claudia Hernández nació en San Salvador, El Salvador en 1975. Ha dedicado la mayor parte de su obra a la narrativa breve, hecho por el cual fue galardonada con el Premio Internacional de Cuento Juan Rulfo en Francia (1998), y el de la Fundación Anne Seghers en Alemania (2004). Dentro de la producción literaria de Hernández se destacan en el género del cuento títulos como: Otras ciudades (2001), Olvida Uno (2005), De fronteras (2007), La canción del mar (2007) y Causas Naturales (2013). Esta escritora, además de sus varios libros de cuentos, posee en su aval literario tres novelas: La han despedido de nuevo (2016), Roza, tumba, quema (2017) y El verbo J (2018).

Ahora bien, la cuentística de Hernández a menudo tematiza la violencia, la muerte y lo grotesco. La inclusión de estos tropos en su narrativa ha hecho que algunos críticos literarios consideren que ciertas obras de esta cuentista pueden ser analizadas dentro del marco teórico de la estética de la violencia y el cinismo. Conviene señalar que la definición de cinismo utilizada en este breve estudio coincide en parte con el criterio de Timothy Bewes, quien en su obra Cinismo y Posmodernidad define el cinismo como: "una reacción

\footnotetext{
Para propósito de este análisis hemos seguido la propuesta expresada por Beatriz Cortez en su obra Estética del cinismo: pasión y el desencanto en la literatura centroamericana de posguerra (2010). Este pensamiento teórico se emplea aquí desde la perspectiva analítica en la producción narrativa centroamericana que aborda temáticas como el desencanto, la desesperanza, la violencia y el cinismo desde mediados hasta finales del siglo XX.
} 
melancólica de autocompadecimiento hacia la aparente desintegración de la realidad política y de las ideologías totalizantes" (116). También estamos en consonancia con el concepto de cinismo en la literatura de posguerra expresado por Beatriz Cortez, quien señala que:

El proyecto cínico no ofrece otra salida de su ámbito sino por medio de la autodestrucción [...] que culmina con el resquebrajamiento de los proyectos utópicos que movían al sujeto a actuar en la cultura revolucionaria, y también con el sujeto colectivo e individual, la erradicación de su poder para actuar, el desmembramiento del cuerpo del sujeto, la desesperanza, la impotencia, y la muerte (131).

O sea, el desmembramiento del cuerpo del sujeto, la desesperanza, el desencanto, la impotencia y la muerte son, precisamente, algunos de los elementos imbuidos en las obras que se analizan en este breve estudio. Por tanto, el cinismo cumple con el acometido de develar la posición autoral de Hernández con respecto a los procesos sociohistóricos vividos en El Salvador a raíz de la guerra y el periodo de posguerra.

Como punto de partida del análisis se han seleccionado tres cuentos extraídos de su colección de relatos breves titulada De fronteras (2007). En esta obra los temas van desde las situaciones en que prima la violencia, hasta la omnipresencia de la muerte. Los personajes de esta colección de historias breves están dañados, marcados por la violencia, el sufrimiento y un profundo desencanto inducido por esa triste realidad que les circunda, coincidiendo así con la opinión manifestada por Cortez cuando expresa que "[a]l transcender los límites marcados por los proyectos revolucionarios, estos textos de ficción exploran los deseos más oscuros del sujeto, sus pasiones más fuertes y su negociación con el caos que le rodea” (27). Así, en los relatos breves narrados en esta colección no se cuestiona o indaga sobre lo violento, ni se trata de encontrar las causas que originan esa violencia, sino que se le describen al lector las estrategias de los personajes para enfrentar las situaciones, sumergiéndole en una atmósfera impregnada de surrealidad.

El primer cuento de nuestro análisis se titula "Mediodía en la frontera". En síntesis, la historia relata el suicidio de una mujer en el baño público de una frontera desconocida, teniendo como único testigo dialógico a un perro callejero. La frivolidad e indiferencia con que el narrador omnisciente cuenta la historia están en paralelo con la desolación del lugar que es, sobre todo, un sitio de convergencias, un centro para la transitoriedad. Además, la 
historia solamente gira alrededor de dos personajes: una mujer, cuyo nombre e historia se desconocen, y el perro hambriento y hasta cierto punto cínico.

Tras la lectura, uno de los elementos que sobresalen de este relato breve, es la atribución de características humanas al animal. Mediante la personalización del can, Hernández le inserta a su narración una profunda subjetividad, la cual reverbera a través de lo grotesco y lo irracional, convirtiéndose así estas en las temáticas que engranan la maquinaria narrativa de la escritora, y de lo cual se hablará más adelante.

Otro detalle resaltante es la tergiversación de roles en los personajes. La mujer -quien representa lo humano- comete un acto autodestructivo, salvaje e irracional -además de colgarse se mutila también la lengua-como lo demuestra el siguiente fragmento extraído del cuento: "Ante sus ojos amarillos de perro, hay una mujer con sangre en la blusa y una lengua en las manos. Sabe que la lengua es de ella porque sus ojos aun le tiemblan del dolor y hay marcas de violencia alrededor de su boca" (Hernández 101). El perro, que es la bestia despojada de raciocinio por naturaleza, es en esta historia capaz de discurrir y pensar como un ser humano. De ahí, que en el pasaje anterior observamos cómo, en la ficción fantástica de Hernández, el ser humano se animaliza y la bestia se humaniza. Sobre este recurso literario, Fabián Alfredo Iglesias enfatiza en uno de sus ensayos que:

La representación de universos literarios cuyas acciones sean llevadas a cabo por seres con apariencia animal, es de antigua data. Sin embargo, según las funciones que la literatura haya asumido para cada época, las leyes genéricas y los estilos individuales de cada autor, estos personajes zoomorfos han adquirido roles y sentidos diferentes (4).

Este recurso literario de la animalización de los personajes, esgrimido magistralmente por Hernández, ha sido empleado en la literatura por disímiles autores en diferentes épocas y latitudes. Muestra de esto es Franz Kafka (1883-1924), uno de los escritores más reconocidos por esta técnica, en cuyas narraciones encontramos la representación de animales humanizados o viceversa. Este mecanismo literario es utilizado para transportar a los lectores hacia un mundo disparatado e irracional, algo muy similar a lo que realiza la cuentista que estamos estudiando.

En Centroamérica, el conocido escritor y cuentista guatemalteco/hondureño Augusto Monterroso (1921-2003), emplea esta misma herramienta en sus cuentos/fábulas, otorgándole a sus personajes-animales la capacidad del 
raciocinio. De esta suerte, se le otorga al animal el poder-paradójicamente- de corporizar y mentalizar lo humano. Para Rodolfo Modern, la animalización de los caracteres literarios es una "metáfora antropológica":

Es, si se quiere, una extensa metáfora desarrollada mediante la paradoja que consiste en darle al animal las posibilidades de resolver enigmas primordialmente reservados al hombre, y que éste ha fracasado en solucionar satisfactoriamente. El animal, en cuanto se parece al hombre -lo anticipamos- también es susceptible al fracaso (203).

Además, como ya se ha dicho anteriormente, se observa en este cuento la sugerencia de que el animal -ser irracional por naturaleza- es capaz de pensar. Es decir, en este caso Hernández le atribuye una capacidad analítica al personaje, manifestándose la misma a lo largo de la historia y que, en cierta forma, señaliza un tipo de "conciencia" en el personaje canino, lo que se puede comprobar en el siguiente pasaje del relato: "-Comprendo-dice el perro. Y realmente comprende...” (1). En relación con el elemento de la conciencia dentro de la literatura, Hilda Gairaud opina que:

La consciencia, un modo de articulación del pensamiento inconsciente que, en los textos, resulta ser una forma incoherente de comunicación interpersonal [...]. El personaje aparece desestabilizado y desconectado de la realidad, razones por las cuales delira y alucina en su afán por controlar la percepción. Paradójicamente, estos personajes no solo encuentran estabilidad en la incoherencia que, de manera simbólica, podría representar el contexto caótico en el cual habitan (la sociedad) sino que también provocan una risa burlona e irónica en el lector (5).

Por otro lado, el entorno en el que se desarrolla la historia de "Mediodía en la frontera" es un espacio frívolo, carente de vitalidad. El suceso de la trama es narrado por medio de un lenguaje conciso y económico en palabras - una de las principales características del género del cuento-, contenido en oraciones breves y párrafos escuetos: otra herramienta empleada por esta escritora para abandonar a la imaginación del lector la subjetividad soterrada en su estrategia narrativa.

Igualmente, los personajes de este cuento habitan, al igual que en muchas otras de sus historias, en un espacio anónimo donde la muerte y la violencia son los ingredientes principales. Hernández no le entrega al lector relatos 
placenteros utilizando el locus amoenus ${ }^{2}$. Al contrario, un locus terribilis es el escenario que se presta a la anonimidad plasmada en este (y otros) cuento(s) según la perspectiva autoral de Hernández, haciendo que la(s) trama(s) encaje(n) en lo grotesco de la(s) historia(s), ubicadas -muchas de ellas- en espacios urbanos.

En este sentido, Linda J. Craft destaca que "[e]1 espacio anónimo trastornado lleva a la fragmentación de la subjetividad, un estado doloroso de desorientación, y el anhelo de la reintegración de espacios que tengan significación" (189). De esta suerte, nos encontramos al personaje de la mujer en "Mediodía en la frontera" deseando morir, quizá porque ha perdido la fe en su humanidad, y se siente desorientada o confundida por una crisis existencial. Las verdaderas razones no son dilucidadas. La voz narrativa solamente nos deja saber, cínicamente, que el personaje: "Quiere ser una ahorcada feliz" (Hernández 103). Así, la cuentista deja a merced de la subjetividad generada por la mente lectora las razones, conclusiones e incógnitas que pudieran asomarse durante la lectura de su narrativa.

En los relatos breves de Hernández, el humor y lo fantástico constituyen componentes esenciales de su estética narrativa, propuesta a romper con la normativa social y logrando, a través de una reciprocidad, transportar al lector hacia la irrealidad que permean sus cuentos. De ahí que el humor negro en las historias de Hernández deviene en una actitud cínica e irreverentemente distanciadora. Como explica David Roas, el humorismo es empleado "para contrarrestar el miedo a la muerte y al dolor" (71). Creemos entonces que el humor negro, reflejado en los cuentos que se analizan en este estudio, lleva implícita una función transgresiva al desempeñar un papel denunciador con respecto a la marginalización, los mecanismos de violencia y la injusticia social en la nación centroamericana.

Por otra parte, notamos en el relato que el personaje de la mujer ha decidido poner fin a su existencia en un baño público, lugar anónimo y en donde se realizan funciones corporales escatológicas. Esta situación quizá lleve al lector hacia el cuestionamiento del porqué un individuo querría ejecutar un acto de semejante magnitud en un entorno como este. Sin embargo, el personaje logra

Tópico literario muy utilizado en la literatura española durante el Renacimiento, en donde la acción o trama de las historias ocurre en un lugar idealizado, plagado de belleza y tranquilidad, marco perfecto para el amor ideal. 
su acometido a través de un suicidio por ahorcamiento, narrado fríamente en el siguiente pasaje de la obra:

\author{
Se cuelga. \\ Patalea. \\ Queda sin movimiento. \\ No respira. \\ Está muerta. (Hernández 2).
}

La cotidianidad trasmitida a través del lenguaje en la descripción de este hecho es uno de los elementos que más sobresalen en De fronteras. En este sentido, con respecto al uso del lenguaje por la cuentista salvadoreña, Nadine Haas explica que:

La discrepancia entre el contenido y el lenguaje tiene un efecto intenso [...]. El tono racional aumenta el efecto de choque y dejan al lector desconcertado [...]. Un suceso inconcebible es transportado a una situación cotidiana. El lenguaje [...] y la descripción distanciada no dejan lugar para emociones. (15).

Por lo anterior discurrimos que, en el estilo escritural de Hernández, el lenguaje de sus relatos breves realiza una función distanciadora. En otras palabras, la manera sobria de contar los sucesos influye, en este sentido, en el distanciamiento emocional de la lectura al relatar acontecimientos que normalmente serían sucesos atroces, alarmantes e incluso fantásticos, presentados ante el lector como algo consuetudinario.

Así, un perro que es capaz de hablar, dialogar y empatizar con una mujer perturbada mentalmente y que esta, a su vez, se mutile el cuerpo para satisfacer su apetito canino -ella lo alimenta con su lengua lacerada- son, para estos personajes, hechos sin mayores consecuencias, narrados con una frugalidad indiferente y un irrebatible cinismo. Siguiendo este derrotero, para Cortez el cinismo reflejado en la literatura centroamericana de posguerra:

Nos permite liberarnos de la censura y rigidez impuestos por los proyectos revolucionarios sobre la narrativa [...]. El proyecto cínico no ofrece otra salida de su ámbito sino por medio de la auto-destrucción [...] y también con la destrucción del sujeto colectivo e individual, la erradicación de su poder para actuar, el desmembramiento del cuerpo del sujeto, la desesperanza, la impotencia, y la muerte (131). 
El tema de la violencia también juega un importante papel en la cuentística de Hernández. Si bien la violencia en El Salvador pudiera considerarse como un fenómeno social multifacético y complejo que alcanzó niveles inigualables durante el periodo bélico, sus ramificaciones se extienden hasta alcanzar una posición como tema narrativo expresado por los escritores -muchas vecesen un estilo estético caracterizado por el cinismo.

Según manifiestan Werner Mackenbach y Alexandra Ortiz Wallner, “[p] ara la producción literaria en Centroamérica es válida la apreciación de un cierto dominio de la violencia como manifestación estética" (84). Y continúan aseverando que:

La representación literaria de la violencia ya no se limita pues a la esfera de la denuncia, sino que es producida y trabajada estética y literariamente como múltiples narraciones y ficcionalizaciones de los cambios fundamentales que están viviendo las sociedades centroamericanas (93).

En otras palabras, la violencia es representada dentro de la literatura centroamericana de una manera que sobrepasa los límites de la denuncia social. Ahora, escritoras como Hernández, en su ficcionalización de la realidad salvadoreña, reflejan a través de sus historias las transformaciones que se han llevado a cabo en la sociedad de su país mediante una estética literaria distinta donde la violencia es naturalizada.

Ahora bien, como expresa Craft, "[1]a experimentación que hace Hernández con el lenguaje y sus límites, con la metáfora y con la fantasía, la magia y lo onírico es bastante típica de las estrategias narrativas de posguerra y también lo es su intensidad" (183). En relación con lo anterior, concordamos con este razonamiento, ya que al analizar el corpus literario de esta cuentista se puede apreciar cómo las intrusiones de animales y de hechos casi alucinantes sugieren la aparición o la necesidad de que el elemento irracional y lo fantástico estén presentes.

Sin embargo, la maquinaria narrativa de Hernández también funciona con los tropos de la muerte y la violencia como catalizadores de la subjetividad colectiva salvadoreña. Con respecto a este punto, Gairaud subraya que:

Para lograr esto, las representaciones resaltan que alrededor de la degradación se articulan los otros elementos, como el aislamiento, la destrucción, la corrupción, la violencia y la predisposición a la 
muerte, que constituyen la plataforma del estado de normalidad. De este modo, mediante sus representaciones, Hernández enmarca las características de la subjetividad salvadoreña (90).

Dicho de otro modo, esta escritora emplea un modelo estético en su narrativa breve donde es posible percibir que: "existe una asociación metafórica, de las representaciones textuales de violencia en El Salvador con la destrucción y la muerte, esta última se encuentra personificada y traducida en el avistamiento simbólico de "cadáveres" (sujetos) en el mundo cotidiano" (Gairaud 82). O sea, la presencia de la muerte es una representación grotesca de una realidad sobre la cual la autora desea realizar un llamado de atención.

Siguiendo esta misma línea, Rincón-Chavarro indica que "para Hernández la presentación del objeto (la violencia naturalizada) de forma diferente (grotesca) no tiene otro propósito que generar una percepción extraña en el lector sobre eso que se ha normalizado en su sistema de representación" (7). O sea, la provocación de un extrañamiento en el lector es una de las posibles percepciones devenidas tras leer una historia breve como "Mediodía en la frontera".

Pasando a otro de los cuentos examinados en este análisis, observamos también la normalización de lo grotesco en "Manual del hijo muerto". En este cuento la trama, como su título bien indica, es una imitación de la página 23 de una guía para la reconstrucción del cuerpo de un hijo muerto, que además de ser privado de la vida, ha sido desmembrado:

Causa especial emoción reconstruir el cuerpo del niño (24-25 años) que salió completo de la casa hace dos o seis días [...]. Antes de iniciar la labor, se sugiere además cerciorarse que cada una de las partes que le han sido entregadas se corresponda con las señas particulares de su hijo y ensamblen armoniosamente. (Hernández 107).

Además, se dan las instrucciones para superar el dolor de la ausencia del hijo fallecido e ignorar las causas y los causantes de la muerte del hijo, como se describe en el siguiente fragmento:

Preste especial atención a las manos y pies. Estos suelen -si uno se fija muy bien- revelar escenas de padecimiento pre-muerte del hijo en cuestión. Para evitar hundirse en la tentación de elaborar hipótesis y encontrar culpables mediante las señales que dejan, cúbralos con guantes y medias de algodón oscuros. (Hernández 109). 
Aquí también el uso del lenguaje es sucinto. Su efectividad está dada en la cotidianidad impregnada tras la descripción de un evento tan doloroso y trágico como sería el dolor causado por la pérdida de un hijo. También se demuestra en el pasaje anterior la degradación y cosificación del cuerpo humano, pues la escritora establece una comparación del cadáver de la víctima con un pedazo de tela que debe armarse siguiendo las instrucciones de un manual.

De esta manera, el desmembramiento del cuerpo de un joven ${ }^{3}$ que se transforma en una pieza de tejido para coser, un objeto trivial que encarna la crueldad, la violencia y el terror sufridos por la sociedad salvadoreña de posguerra. En este sentido, Gairaud asevera que, para Hernández, "los cuerpos y cadáveres constituyen la materialización de la memoria pública y privada de quienes fueron víctimas de la violencia" (96). Dicho de otro modo, mediante la manipulación del cuerpo humano, ya sea muerto o mutilado, la creadora invoca el recuerdo de los horrores y el estropicio social del cual fue testigo la nación centroamericana.

Asimismo, con este relato nos hallamos otra vez frente a la implantación de una realidad que sostiene en sí misma disímiles estratos contenidos en una normalización reflejada a través de la sobriedad del estilo narrativo de Hernández en De fronteras. Por una parte, el hecho de esperar la llegada del hijo como si fuera un producto de catálogo comercial. Luego, el seguimiento de las instrucciones para el control del dolor y el desmembramiento del hijo, añadida a la orientación de no realizar ninguna búsqueda de los responsables, imposibilita lo que dentro de la normalidad instigaría un impulso común posasesinato.

En efecto, la manipulación de los cadáveres sugiere en la obra de Hernández cierta alusión a los flagelos que han tenido que encarar los salvadoreños a raíz de la violencia militar sufrida en su país. Las matanzas, los asesinatos, los secuestros y violaciones, al parecer constituyen un planteamiento que suscita un presente de justicia en la sociedad salvadoreña, la cual Hernández intenta insinuar en sus cuentos. También, la mutilación del cuerpo funciona como un elemento de expropiación dentro de la narrativa de esta cuentista.

No obstante, como se ha mencionado anteriormente, en el tratamiento corpóreo en este relato breve y en el resto de la obra de la escritora que

Esto pudiera entenderse como una referencia a la forma en que los militares asesinaban a los niños desprotegidos en las llamadas "Operaciones Limpieza", llevadas a cabo durante el periodo de conflictos bélicos en El Salvador (1980-1992). 
estamos analizando permea un cinismo que se corresponde con el razonamiento teórico de Cortez, que considera el cinismo como "una trampa que constituye la subjetividad por medio de la destrucción del ser a quien constituye como sujeto" (26). Entonces, en resonancia con este planteamiento, la narrativa cínica de la cuentista salvadoreña busca una estética alternativa que no determine la renuncia a la construcción de subjetividades independientes, especialmente a la preeminencia de la vida y la felicidad del ser humano ante el horror, la violencia y la muerte experimentadas durante la guerra civil salvadoreña.

Como hemos venido diciendo, la mayoría de los cuentos contenidos en De fronteras reflejan una violencia multifacética, una tensión circulatoria omnipresente que inunda cada una de las historias. A través de personajes incompletos, mutilados, violentados y afectados por la muerte, la autora realiza una reflexión de la fisicidad que contrasta con la prepotencia, la agresividad y las estrategias del poder. De esta suerte, Hernández exterioriza los mecanismos que instauran las distintas dinámicas sociales como las relaciones interfamiliares y la sexualidad.

Para concluir este análisis, tenemos el relato breve "Hechos de un buen ciudadano (Partes I y II)". La primera parte narrada en primera persona comienza con un narrador protagonista que encuentra el cadáver de una muchacha asesinada en el piso de su cocina, a la cual da por nombre Lívida por su apariencia y el color amoratado de sus labios. Ante el espeluznante hallazgo, el personaje protagónico, también desde el anonimato como en las anteriores historias, se sorprende por la minuciosidad y exquisitez del "trabajo" del homicida, y expresa: "He visto muchos asesinados en mi vida, pero ninguno con un trabajo tan impecable como el que le habían practicado a la muchacha” (Hernández 17). Otra vez, aquí divisamos la frugalidad del lenguaje y la sobriedad casi humorística con la que la autora nos describe esta inusitada situación. El personaje no alerta a las autoridades sobre el incidente, sino que asume la "normalidad" del hecho y decide poner un anuncio en el periódico para encontrar a los familiares de la víctima.

En la segunda parte del cuento, el autodenominado "buen ciudadano" recibe muchas llamadas de individuos que están necesitando consejos sobre qué hacer con los muertos que tienen en sus hogares -la tenencia de muertos en las residencias al parecer es muy común para ellos--. Consecuentemente, el personaje convoca a una reunión en su casa donde les explica cómo resolver esta situación: salando los cuerpos, llamando a los periódicos y trozando los cadáveres. 
De este modo, el texto sugiere una cotidianidad que impresiona al lector. En el siguiente fragmento apreciamos la parsimonia de la narración: "La espera fue agradable. Ellos llevaron té, café, galletas y otras bebidas y bocadillos para acompañar la conversación. La pasamos muy bien" (Hernández 40). Aquí podemos afirmar que la sobriedad casi se fusiona con un humor negro y macabro, por medio del cual la cuentista trata de atraer la atención en su narrativa breve.

De ahí que, a nuestro parecer, en dicha estrategia escritural se percibe la existencia de una dicotomía basada en la irrupción de los espacios tanto externos como internos dentro del universo de los personajes. Durante la lectura de la primera parte de este relato, observamos que, al igual que en "Manual del hijo muerto", el escenario es trasplantado a la ciudad: el protagonista encuentra el cadáver en la cocina de su casa.

Ahora bien, el protagonista adopta una actitud pasiva ante la situación que bien pudiera tener matices de cuento policíaco -meticulosidad del crimen, búsqueda del arma del delito, estado del cadáver, chequeo de las cerraduras, limpieza de la sangre-, sino fuese por el vuelco que da la narración cuando el personaje, "como cualquier buen ciudadano habría hecho" (Hernández 17), pone el anuncio en el diario, y por este hecho se autoproclama "buen ciudadano". Por este motivo, ayuda con sus futuras acciones -asistencia a los familiares de las víctimas, labor socioeducativa mediante los consejos de cómo cuidar de los cadáveres y alimentación de los menos privilegiados-al buen desempeño social dentro de la comunidad para recibir la aprobación de la sociedad. Sobre este aspecto, Cortez apunta que la exposición de la función social del sujeto (privado o colectivo) después del trauma sufrido por los horrores bélicos es una de las características de la literatura centroamericana de posguerra (16).

Asimismo, se destaca nuevamente la utilización del lenguaje y las adjetivaciones que enfatizan esa normalidad intrínseca de la narración. El cadáver de la joven es descrito por el narrador como un pedazo de carne que "estaba fresco" (Hernández 17), algo que para el lector no sería lo que normalmente se esperaría de un occiso. Intencionalmente, esta es la forma en que la Hernández hilvana irónicamente, con toques humorísticos $\mathrm{y}$ un distorsionado cinismo, la indiferencia y banalidad con la que el buen ciudadano asume su presunta tarea cívica. En esta historia, la muerte y el hallazgo de cadáveres en las casas es un acontecimiento visto con una serenidad irónica, en donde el pragmatismo del personaje resulta un hecho digno de admiración, pero que no deja de inquietar al lector, pues como bien 
destaca Ignacio Sarmiento: "Queda completamente claro que identificar a las víctimas y encontrar a sus familiares no traerá consigo ningún tipo de justicia o reparación por los crímenes cometidos. En este contexto, todas las muertes están cubiertas ineludiblemente por un hálito de impunidad" (401). En efecto, en la lectura no encontramos ninguna clase de cuestionamientos o interrogantes acerca de la procedencia de los occisos por parte de los miembros o ciudadanos en esta historia. La dura realidad de la muerte es aceptada con toda trivialidad y la presencia de los muertos se convierte en un evento al que simplemente se debe dar solución; algo que visto desde un ángulo diferente podría estar en consonancia con los razonamientos teóricos de Cortez en cuanto a la estética del cinismo.

Empero, este elemento o fenómeno más bien pudiera alertar al lector de la existencia del contraste entre lo real y lo imposible de manera alarmante. El lector se siente desprotegido ante un mundo exterior que, a través de esta desordenada invasión de cuerpos exánimes, de forma absurda y violenta, invade el espacio familiar del hogar. Dichas incursiones sugieren una alusión a la realidad que se vive en El Salvador, convirtiéndose en una potente metáfora explorada en múltiples dimensiones por Hernández en su intento de conservar en la memoria colectiva a aquellas víctimas que murieron a causa de las confrontaciones militares.

Como ha señalado Mackenbach, estos relatos también pueden ser leídos como historias que "persiguen las íntimas perversiones y heridas de los individuos, como sintomáticos de una reciente salida de la experiencia traumática de la guerra" (89). O sea, podríamos leer a Hernández desde una perspectiva literaria donde, por medio de un lenguaje sobrio y directo, en historias saturadas de personajes indolentes que acatan sin cuestionamientos las situaciones más inusuales de violencia y muerte como parte de una realidad, se trabaja en paralelo con el trauma psicológico producido durante el periodo bélico.

A nuestro juicio, la narrativa de Hernández, además de atrapar a los lectores con su destreza estilística, también encuadraría dentro de las narrativas que se escudriñan académicamente bajo las estéticas de la violencia y del cinismo dentro de la llamada literatura centroamericana de posguerra. Pues, como bien hemos venido demostrando a lo largo de este análisis, los mecanismos que conforman la maquinaria narrativa de esta escritora salvadoreña son, precisamente, los temas de la violencia, la muerte y la subjetividad.

Para finalizar, en la colección de cuentos De fronteras, la muerte ejerce una importante función simbólica a la cual se aferran muchas de sus historias. 
Así, la mutilación del cuerpo en los tres relatos analizados -además de ser el hilo conductor de las historias- subvierte la realidad para convertirla en subjetividad. En otras palabras, la carencia de contextualizaciones o explicaciones para las situaciones de violencia y dolor que se presentan en los cuentos intensifica el impacto de la narrativa en el lector, al posibilitar que él/ella mismo/a rellene los vacíos dejados por la escritora.

De esta suerte, Hernández nos acerca, mediante un estilo único, a las exploraciones sobre una realidad social violenta y degradada en El Salvador de la posguerra. Sus personajes proponen otro tipo de colectividad mucho más allá de la homologación definida por la sociedad. Ellos y ellas sobreviven, ya sea atrapados en cuerpos deformes, mutilados o desmembrados, en un universo casi fantástico, donde, gracias a su creadora, se abren otras contingencias al imaginarse una nueva manera de estar en el mundo que proporciona respuestas discordantes ante la muerte, lo violento y la subjetivación. Finalmente, lejos de ambicionar abarcarlo todo sobre esta temática, con este análisis apenas se ha pretendido levantar una punta del velo que la cubre, con la esperanza de motivar a otros a explorar el amplio derrotero de la literatura de posguerra.

\section{BIBLIOGRAFÍA}

Bewes, Tiмothy. Cinismo y Posmodernidad. Verso, Londres, 1997.

Callsen, Beritt. "Cuerpo, des/uso y subjetivación en Hernández, Bellatin y Nettel”. ¿Discapacidad?: Literatura, teatro y cine hispánicos vistos desde los disability studies. Julio Checa y Susanne Hartwig (eds.), Nueva York, Peter Lang, 2018, pp. 223-238.

CORTEZ, BeATriz. Estética del cinismo: pasión y el desencanto en la literatura centroamericana de posguerra. Ciudad de Guatemala, F\&G Editores, 2010.

Gairaud, Hilda. "Sistemas de exclusión y violencia en relatos de los salvadoreños Manlio Argueta y Claudia Hernández". Revista de Filología y Lingüística de la Universidad de Costa Rica 31, N¹, 2014, pp. 77-104.

"Rutas de muerte en la narrativa de Claudia Hernández". Revista de Lenguas Modernas 22, 2015, pp. 203-215.

Gentile, Melania. "La cotidianidad de la muerte en los cuentos fantásticos de Claudia Hernández”. Revista de Lenguas Modernas 27, 2017, pp. 139-147.

HAAS, NADINE. "Representaciones de la violencia en la literatura centroamericana". German Institute of Global and Area Studieds (GIGA) 148, 2010, pp. 1-26.

Hernández, Claudia. De fronteras. Guatemala, Editorial Piedra Santa, 2014.

Jossa, Emanuela. "Cuerpos y espacios en los cuentos de Claudia Hernández". Centroamericana $24, \mathrm{~N}^{\circ} 1,2014$, pp. 5-37. 
Mackenbach, Werner y Alexandra Ortiz Wallner. “(De)formaciones: violencia y narrativa en Centroamérica”. Iberoamericana VIII, N³2, 2008, pp. 81-97.

Modern, Rodolfo. Aproximación a una antropología kafkiana en Franz Kafka. Homenaje en su centenario 1883-1983. Buenos Aires, Centro de Estudios Germánicos, Facultad de Filosofía y Letras, p. 203.

Ortiz Wallner, Alexandra. "Narrativas centroamericanas de posguerra: problemas de la constitución de una categoría de periodización literaria”. Iberoamericana 5, $\mathrm{N}^{\circ} 19,2005$, pp. 135-147.

"Claudia Hernández-Por una poética de la prosa en tiempos violentos". LEJANA. Revista Crítica de Narrativa Breve 6, 2013, pp. 1-10.

Rincón-Chavarro, María C. "De violencia, de normalización y De Fronteras". Catedral Tomada: Revista de Crítica Literaria Latinoamericana 1, N¹, 2013, pp. 106-122.

RoAs, DAvid. Tras los límites de lo real: una definición de lo fantástico. Editorial Páginas de Espuma, 2011.

SARmiento, Ignacio. “¿Qué hacer con los muertos? Claudia Hernández y el trabajo del duelo en la posguerra salvadoreña”. Revista Canadiense de Estudios Hispánicos 41, N², 2017, pp. 395-415. 